\title{
The impacts of the health policy reform under the national health insurance on medicine use and treatment cost: A study on type-2 diabetic mellitus patients in Jakarta, Indonesia
}

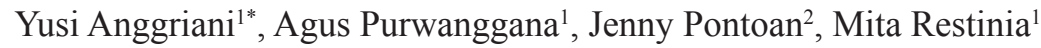 \\ ${ }^{1}$ Faculty of Pharmacy, University of Pancasila, Jakarta, Indonesia \\ ${ }^{2}$ National Institute of Saint and Technology, Jakarta, Indonesia.
}

\begin{tabular}{l}
\hline ARTICLE INFO \\
\hline Received on: 07/03/2019 \\
Accepted on: 01/08/2019 \\
Available online: 03/12/2019 \\
\hline Key words: \\
NHI, medicine use, cost of \\
treatment, diabetes mellitus.
\end{tabular}

\section{INTRODUCTION}

In January 2014, the Indonesian government implemented a national health insurance (NHI) program called Jaminan Kesehatan Nasional (JKN). Prior to 2014, Indonesian health care had traditionally been fragmented into private insurance schemes and limited social health insurance schemes, covering the formal sector, named Asuransi Kesehatan-ASKES (i.e., health insurance for civil servants, the police, and the military). All ASKES patients transformed into members of NHI when it was implemented. Members of NHI are Indonesians who either pay the premium themselves or whose premiums are paid by the government and employer (MoH, 2013). Insurance premiums for civil servants and soldiers are deducted monthly from their salary, in an amount set

\section{${ }^{*}$ Corresponding Author}

Yusi Anggriani, Faculty of Pharmacy, University of Pancasila, Jakarta, Indonesia.E-mail:yusi1777@yahoo.com at $5 \%$ per month per worker. The government pays the premiums for poor people.

Under the implementation of NHI, the government conducted several reforms on health policy (including payment methods, the medicine utilization policy, and procurement). The policies are applied in the selection process through the national formulary; a list of chosen medicines that are needed and which must be available in health care facilities as a reference for the implementation of NHI. The prices of national formulary medicines are regulated under Presidential Decree No. 111 of 2013, which states that the "list and highest prices of medicines and disposable medical materials are determined in accordance with the law" (Presidential Decree, 2013). To improve this effectiveness, efficiency, and transparency, the mechanism of medicine provision is e-purchase based on the e-Catalog (the electronic catalog). The pharmaceutical industries and health facilities can access it through an online link (https://e-katalog.lkpp.go.id/backend/katalog/list_produk/74).

The government also changed the payment method from fee for service (FFS) to the Indonesian Case Base Group (Ina- 
CBG) payment method. Ina-CBG was adopted by Drug-related Group (DRG). DRG is a system for classifying patient care by relating common characteristics such as diagnosis, treatment, and age to an expected consumption of hospital resources and length of stay. ASKES used the FFS payment method, where all treatment services, including medicines, were covered by insurance. However, NHI uses the Ina-CBG payment method, where the treatment cost is limited, based on one's package $(\mathrm{MoH}, 2014 \mathrm{a})$. The package rate of Ina-CBGs includes the cost of a doctor, administration, medical examination, laboratory tests, and medicines for only 7 days. For chronic diseases, Ina-CBGs outpatient package rate is classified by the type of hospital and the region. For example, in a type A (tertiary) hospital, the Ina-CBG package rate for type 2 diabetes mellitus (T2DM) outpatients in Jakarta is IDR. 362,000 (USD 27,618), and for a type B (secondary) hospital, the cost is IDR. 165,000 (USD $12,622)(\mathrm{MoH}, 2014 \mathrm{~b})$. The package rate should be appropriate with the treatment needed, without affecting the quality of health care services (Chawla and Ellis, 2000; Stewart and Horgan, 2011).

Currently, the implementation of NHI toward universal health coverage (UHC) has an impact on the access to medicines, which has become an important issue among developed and developing countries. Faden et al. (2011) reported that the implementation of health insurance contributed to improve access to pharmaceuticals and outcomes in low- and middle-income countries. In Sudan, after the implementation of UHC, medicine usage increased significantly (Mousnad et al., 2017) and there were similar findings in Thailand (Jung et al., 2018). Changes in payment methods in France and the United States also increased patient access to health care (Benjamin et al., 2014) while in Korea, changing the payment method from FFS to a CBGs system helped medical service expenditures become manageable (Kwon, 2003). Therefore, the implementation of changed policies under the NHI could impact treatment costs and prescribed medicines, including those for patients with a chronic disease.

As a chronic disease, T2DM requires continuous and comprehensive treatment. According to the International Diabetes Federation (2015), Indonesia ranks seventh out of ten countries, with the highest prevalence of diabetes and 10 million cases of adult diabetes have been recorded (IDF, 2015). Current data have also shown that the number of people with DM in hospital increased after the implementation of NHI (BPJS, 2017).

The Ina-CBGs package payments may influence medicine usage and treatment cost. Therefore, assessing the treatment of DM after the implementation of the NHI is essential. In May 2014, the study on the early implementation of NHI with respect to the treatment of T2DM revealed that patients received about two to eight types of medicines. The most frequent number of medicines prescribed were four to six medicines (Wijaya et al., 2015). Nevertheless, studies on medicine prescription before the NHI are limited. Therefore, this study aimed to assess the impacts of the policy reforms under the NHI on medicines use and treatment cost in T2DM outpatients in five hospitals in Jakarta.

\section{MATERIALS AND METHODS}

\section{Study design}

The study applied a longitudinal time series design for evaluating the effect of the implementation of the NHI (6 months before and 24 months after the NHI) in five hospitals in Jakarta. According to Wagner et al. (2002), the best method to evaluate the effect of an intervention is the interrupted time series with a quasi-experimental design of 12-point data before and after the intervention. Nevertheless, the study result can inform some significant changes after the implementation of the NHI.

The hospitals comprised two type A (tertiary healthcare centers) and three type B (secondary healthcare centers) hospitals. Patients' treatment and cost data were observed from July 2013 to December 2015

\section{Source of data}

The patients' treatment data, including diagnosis code, laboratory test, and medicine prescribed (dosage form, dose, and frequency), were obtained from medical records. The costs of treatment and medicines were collected from the finance department and pharmacy.

\section{Inclusion and exclusion criteria}

The patients included in this study were T2DM patients without complication, ASKES members before the implementation of the NHI, who controlled their diseases at least six times before and after the NHI, and who have complete data on treatment and cost during the study period. T2DM patients with comorbidity diseases and uncompleted data were excluded.

\section{Study indicators}

Each indicator was analyzed based on the period before and after the implementation of the NHI and classified by hospital type. These indicators are as follows:

\section{Average number of medicines prescribed}

This indicator refers to the number of medicines prescribed to patients, including DM or non-DM medicines. It is calculated by dividing the total number of prescribed medicines in one period by the number of patients.

\section{Average number of DM medicines and non-DM medicines}

This indicator refers to the DM medicines defined as medicines in the prescription and listed in the DM Therapy Guideline from the Indonesian Association of Endocrinology (2015). The prescription medicines not listed in the DM treatment guidelines are classified as non-DM medicines. This indicator is calculated by dividing the number of DM or non-DM medicines prescribed in one period by the number of patient visits.

\section{Average number of generic and non-generic medicines}

This indicator refers to the prescription of medicines with international non-proprietary names (INN). It is calculated by dividing the number of medicines prescribed with the INN name in one period by the total number of medicines prescribed.

Cost

All indicators related-cost in this study were recorded in USD based on hospital or payer (NHI) perspective. The currency of 1 USD is equivalent to IDR 13,155 (22 August 2016). The author calculated cost based on Ina-CBGs package rate. Every year, the package rate might be changed by the government $(\mathrm{MoH})$. The changed has been considered by the inflation rate. Therefore, in this study, the author did not adjust the inflation rate. 


\section{Average cost of treatment}

The cost of treatment is the total cost of patient care and it consists of administrative, medical examination, laboratory test, and medicine costs. It is calculated by dividing the total cost of patient treatment in one period by the number of patient visits in the period.

\section{Average cost of medicines}

The cost of medicine is calculated by the total cost of medicines prescribed to the patients divided by the number of prescriptions. The medicines are classified into two categories, namely, DM medicines and non-DM medicines.

\section{Percentage cost of medicines compared with the cost of treatment}

Cost of medicines compared with the cost of treatment is calculated as the cost of medicines divided by the total cost of treatment. This data is calculated based on the individual patients then take the average.

\section{Cost of DM and non-DM medicines}

The cost of DM or non-DM medicines is calculated as the total cost of DM or non-DM medicines divided by the number of patient with the prescription. This data is calculated based on the individual patients then take the average.

\section{Statistical analysis}

The data were analyzed in five hospitals and sub-analyzed based on the type of hospital. Data were classified into two parts: the data collected before the implementation of the NHI (July 2013December 2013) and the data collected after the implementation of the NHI (January 2014-December 2015). The values of each indicator before and after the implementation of the NHI were compared by using Statistical Package for the Social Sciences $\left(\right.$ SPSS $^{\circledR}$ version 19). The data were non-normally distributed and showed heterogeneity of variance. Thus, the non-parametric (Wilcoxon) test was performed to compare all the parameters. A $p$-value of less than 0.05 was considered statistically significant. Each indicator was presented as the data trend of the month value.

The impact of the NHI policy on the medicine used and the cost was assessed by observing the changing of the indicators before and after the implementation of NHI.

\section{RESULTS}

\section{Patients' characteristics}

The study sample comprised of 466 eligible T2DM patients. A total of 177 patients came from the type A hospitals and 289 patients from the type B hospitals. The number of female T2DM patients was higher than that of the males at $258(55.5 \%)$ and $208(44.6 \%)$, respectively. The group with the highest number of patients with T2DM was the group with patients aged 65-74 years old $(40.8 \%)$.

\section{Medicine prescription profile}

The result showed that the NHI had a significant effect on some of the indicators $(p<0.05)$ (Table 1$)$. According to the evaluation of the five hospitals, the significant differences were observed in the medicine used profile (the number of medicines, DM medicines, non-DM medicines, generic medicines, and non-generic medicines). In terms of the cost indicators, the cost of medicines, cost of treatment, and proportion of the cost of medicine compared with cost treatment decreased significantly $(p<0.01)$. Only the cost of non-DM medicines was similar between before and after the NHI.

The analysis by hospital type revealed the different patterns between hospital type A and B. The cost of medicine and treatment in type A hospitals slightly increased but was not significant. The decreasing proportion of medicine cost compared with the treatment cost was not significant $(p>0.05)$. Conversely, in type B hospitals, most of the cost indicators except the non-DM medicine cost decreased significantly $(p<0.05)$.

\section{Average number of medicines prescribed}

The overall results from the five hospitals revealed that the average number of medicine prescribed per patient visit decreased significantly $(p<0.05)$. Further analysis showed a different finding. The number of medicines increased significantly in type A hospitals $(p<0.01)$ but decreased in type B hospitals $(p<0.01)$.

\section{Number of DM and non-DM medicines}

Figure 1 presents the trend of the average number of DM and non-DM medicines prescribed among T2DM outpatients before and after the implementation of the NHI. The trend in all hospitals showed that the number of non-DM medicines prescribed was higher than that of DM medicines. The non-DM medicines prescribed were vitamins and minerals and medicines to treat hypertension, cardiovascular diseases, and hyperlipidemia. Conversely, in both types A and B hospitals at the beginning of the NHI, the number of non-DM medicines slightly decreased and then increased again after 1 year of the implementation of the NHI. In type B hospitals, the number of non-DM medicine was always higher than that of DM medicine, and the non-DM prescriptions in the 2-year period after the implementation of the NHI decreased significantly.

\section{Number of generic and non-generic medicines}

The study found interesting results on this indicator. The positions of generic medicine and non-generic medicine prescription interchanged (Fig. 2). Before the implementation of the NHI, the number of non-generic medicines used was higher than that of generic medicine. By contrast, starting in January 2014, the number of generic medicines used was significantly higher than that of non-generic medicines. The overall pattern in all hospitals was similar to that in the type B hospitals. In the type A hospitals, the number of generic medicines used was higher than that of non-generic medicines at the beginning of the NHI. Six months after the implementation of the NHI, the number of nongeneric medicines used was higher than that of generic medicines and continued to fluctuate. A similar percentage between generic and non-generic medicines was obtained in September-December 2015. In total, the number of generic medicines used increased after the implementation of the NHI.

\section{Cost of treatment}

The overall cost of treatment in the five hospitals decreased after the implementation of the NHI. A sub-analysis of the type A hospitals indicated that the cost of treatment was similar 
Table 1. Comparison indicators before and after the implementation of the JKN among T2DM patients.

\begin{tabular}{|c|c|c|c|c|c|c|}
\hline \multirow[b]{2}{*}{ Indicators } & \multicolumn{2}{|c|}{ Paired differences } & \multicolumn{3}{|c|}{ Number of patients } & \multirow[b]{2}{*}{ Sig ( 2 tailed) } \\
\hline & $\begin{array}{c}\text { Mean } \\
\text { before JKN }\end{array}$ & $\begin{array}{c}\text { Mean } \\
\text { after JKN }\end{array}$ & $\begin{array}{c}\text { After JKN < } \\
\text { before JKN }\end{array}$ & $\begin{array}{c}\text { After JKN > } \\
\text { before JKN }\end{array}$ & $\begin{array}{l}\text { After JKN = } \\
\text { before JKN }\end{array}$ & \\
\hline Number of medicines per patient visit & 5.13 & 4.90 & 191 & 171 & 104 & $0.022^{*}$ \\
\hline Number of DM medicines & 2.12 & 2.38 & 99 & 147 & 220 & $0.000^{*}$ \\
\hline Number of non-DM medicines & 3.03 & 2.56 & 209 & 139 & 117 & $0.000^{*}$ \\
\hline Number of generic medicines & 1.97 & 2.86 & 72 & 291 & 102 & $0.000^{*}$ \\
\hline Number of non-generic medicines & 3.58 & 1.92 & 376 & 28 & 62 & $0.000^{*}$ \\
\hline Value cost of treatment per outpatient/visit (USD & 41.66 & 38.67 & 233 & 233 & 0 & $0.028^{*}$ \\
\hline Value cost of medicine per outpatient/visit(USD) & 42.11 & 30.83 & 258 & 208 & 0 & $0.002^{*}$ \\
\hline Percentage cost of medicines compared with cost of treatment (\%) & 77.09 & 71.68 & 309 & 157 & 0 & $0.000^{*}$ \\
\hline Cost of DM medicines (USD) & 23.09 & 21.53 & 272 & 194 & 0 & $0.000^{*}$ \\
\hline Cost of non-DM medicines (USD) & 11.67 & 11.07 & 222 & 244 & 0 & 0.985 \\
\hline \multicolumn{7}{|l|}{ Type A hospitals ( $N=2$ hospitals; 177 patients) } \\
\hline \multirow[b]{2}{*}{ Indicators } & \multicolumn{2}{|c|}{ Paired Differences } & \multicolumn{3}{|c|}{ Number of patients } & \\
\hline & $\begin{array}{c}\text { Mean } \\
\text { before JKN }\end{array}$ & $\begin{array}{c}\text { Mean } \\
\text { after JKN }\end{array}$ & $\begin{array}{c}\text { After JKN < } \\
\text { before JKN }\end{array}$ & $\begin{array}{c}\text { After JKN > } \\
\text { before JKN }\end{array}$ & $\begin{array}{l}\text { After JKN = } \\
\text { before JKN }\end{array}$ & Sig ( 2 tailed) \\
\hline Number of medicines per patient visit & 5.23 & 5.97 & 46 & 96 & 35 & $0.000^{*}$ \\
\hline Number of DM medicines & 2.33 & 2.93 & 37 & 77 & 63 & $0.000^{*}$ \\
\hline Number of non-DM medicines & 2.92 & 3.02 & 51 & 80 & 46 & 0.198 \\
\hline Number of generic medicines & 1.44 & 3.03 & 9 & 147 & 21 & $0.000^{*}$ \\
\hline Number of non-generic medicines & 3.89 & 2.39 & 140 & 12 & 25 & $0,000^{*}$ \\
\hline Value cost of treatment per outpatient/visit (USD) & 53.00 & 54.13 & 90 & 87 & 0 & 0.852 \\
\hline Value cost of medicine per outpatient/visit(USD) & 42.61 & 47.57 & 84 & 93 & 0 & 0.651 \\
\hline Percentage cost of medicines compared with cost of treatment (\%) & 81.80 & 81.35 & 95 & 79 & 3 & 0.672 \\
\hline Cost of DM medicines (USD) & 30.53 & 35.24 & 99 & 78 & 0 & 0.333 \\
\hline Cost of non-DM medicines (USD) & 11.50 & 12.71 & 76 & 101 & 0 & 0.083 \\
\hline \multicolumn{7}{|l|}{ Type B hospitals ( $N=3$ hospitals; 289 patients) } \\
\hline \multirow[b]{2}{*}{ Indicators } & \multicolumn{2}{|c|}{ Paired differences } & \multicolumn{3}{|c|}{ Number of patients } & \\
\hline & $\begin{array}{c}\text { Mean } \\
\text { before JKN }\end{array}$ & $\begin{array}{c}\text { Mean } \\
\text { after JKN }\end{array}$ & $\begin{array}{c}\text { After JKN < } \\
\text { before JKN }\end{array}$ & $\begin{array}{l}\text { After JKN > } \\
\text { before JKN }\end{array}$ & $\begin{array}{c}\text { After JKN = } \\
\text { before JKN }\end{array}$ & Sig ( 2 tailed) \\
\hline Number of medicines per patient visit & 5.07 & 4.25 & 145 & 75 & 69 & $0.000^{*}$ \\
\hline Number of DM medicines & 2.00 & 2.03 & 62 & 70 & 157 & 0.643 \\
\hline Number of non-DM medicines & 3,09 & 2,28 & 158 & 59 & 71 & $0.000^{*}$ \\
\hline Number of generic medicines & 2.30 & 2.75 & 63 & 144 & 81 & $0.000^{*}$ \\
\hline Number of non-generic medicines & 3.39 & 1.63 & 236 & 16 & 37 & $0.000^{*}$ \\
\hline Value cost of treatment per outpatient/visit (USD & 34.71 & 29.21 & 143 & 146 & 0 & 0.007 \\
\hline Value cost of medicine per outpatient/visit(USD) & 26.91 & 20.57 & 174 & 174 & 0 & $0.000^{*}$ \\
\hline Percentage cost of medicines compared with cost of treatment (\%) & 74.21 & 65.76 & 212 & 77 & 0 & $0.000^{*}$ \\
\hline Cost of DM medicines (USD) & 18.53 & 13.14 & 173 & 116 & 0 & $0.000^{*}$ \\
\hline Cost of non-DM medicines (USD) & 11.78 & 10.06 & 146 & 143 & 0 & 0.120 \\
\hline
\end{tabular}

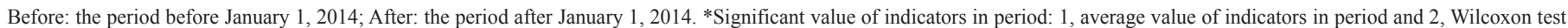
$(p=95 \%)$.

before and after the NHI. The cost of treatment of patients in type B hospitals decreased from USD 34.71 to USD 29.21.

\section{Cost of medicines}

As shown in Figure 3, the cost of medicine decreased at the beginning of the NHI and then fluctuated at 1 month after the NHI. It was constant after 1 year of the NHI. The cost of medicine per patient decreased from IDR 600,000 (USD 45.80) to IDR 400,000 (USD30.53) at the beginning of the NHI (January 2014). In the type A hospitals, the cost of medicine was higher than that before the NHI after 1 year of implementation. In type B hospitals, the cost of medicine decreased at the beginning of the NHI. Overall, the trend indicated that the cost was lower than that before the NHI (p-value $=0.002)$. 

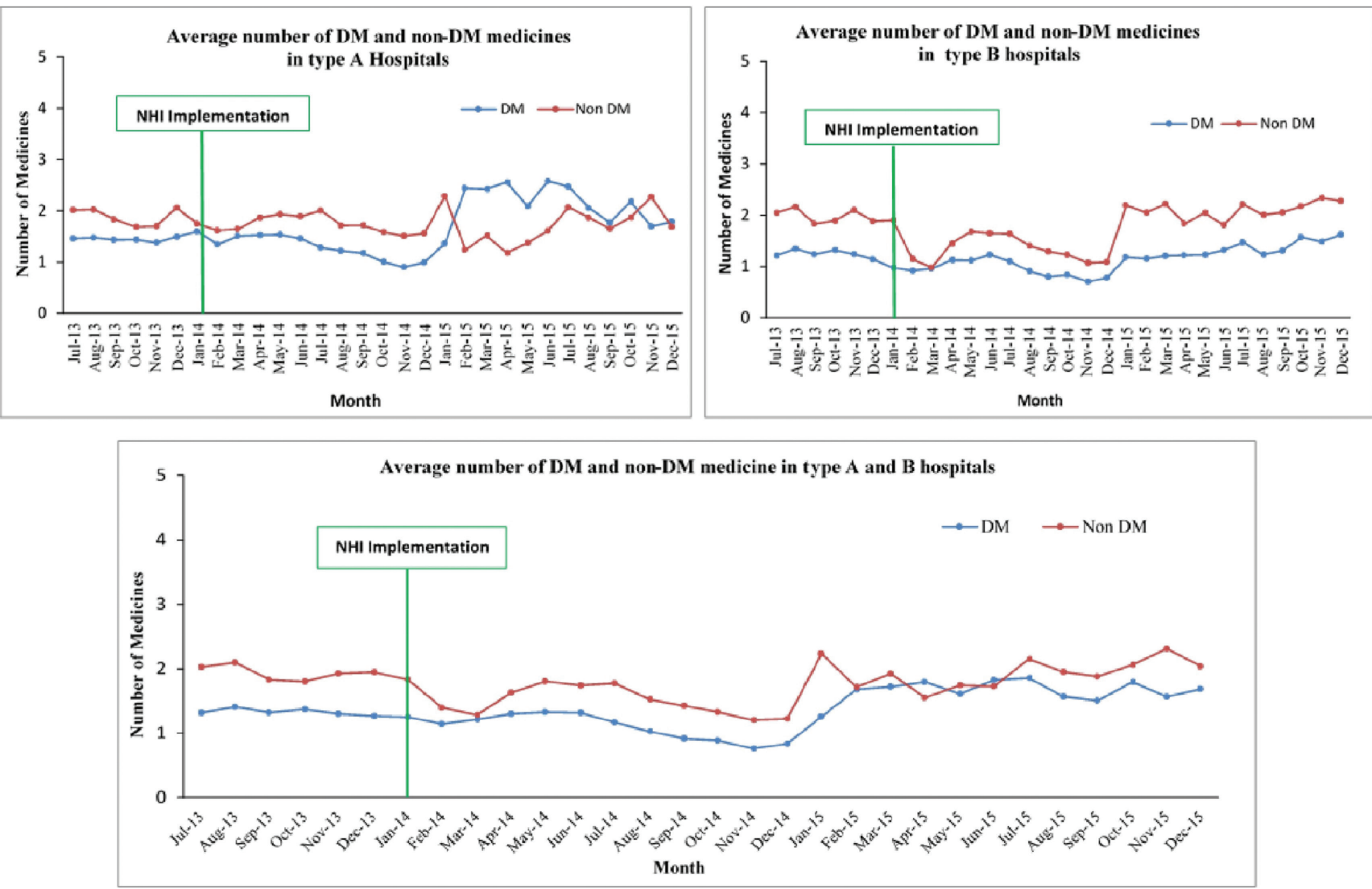

Figure 1. Average number of DM and non-DM medicines per patient per month.
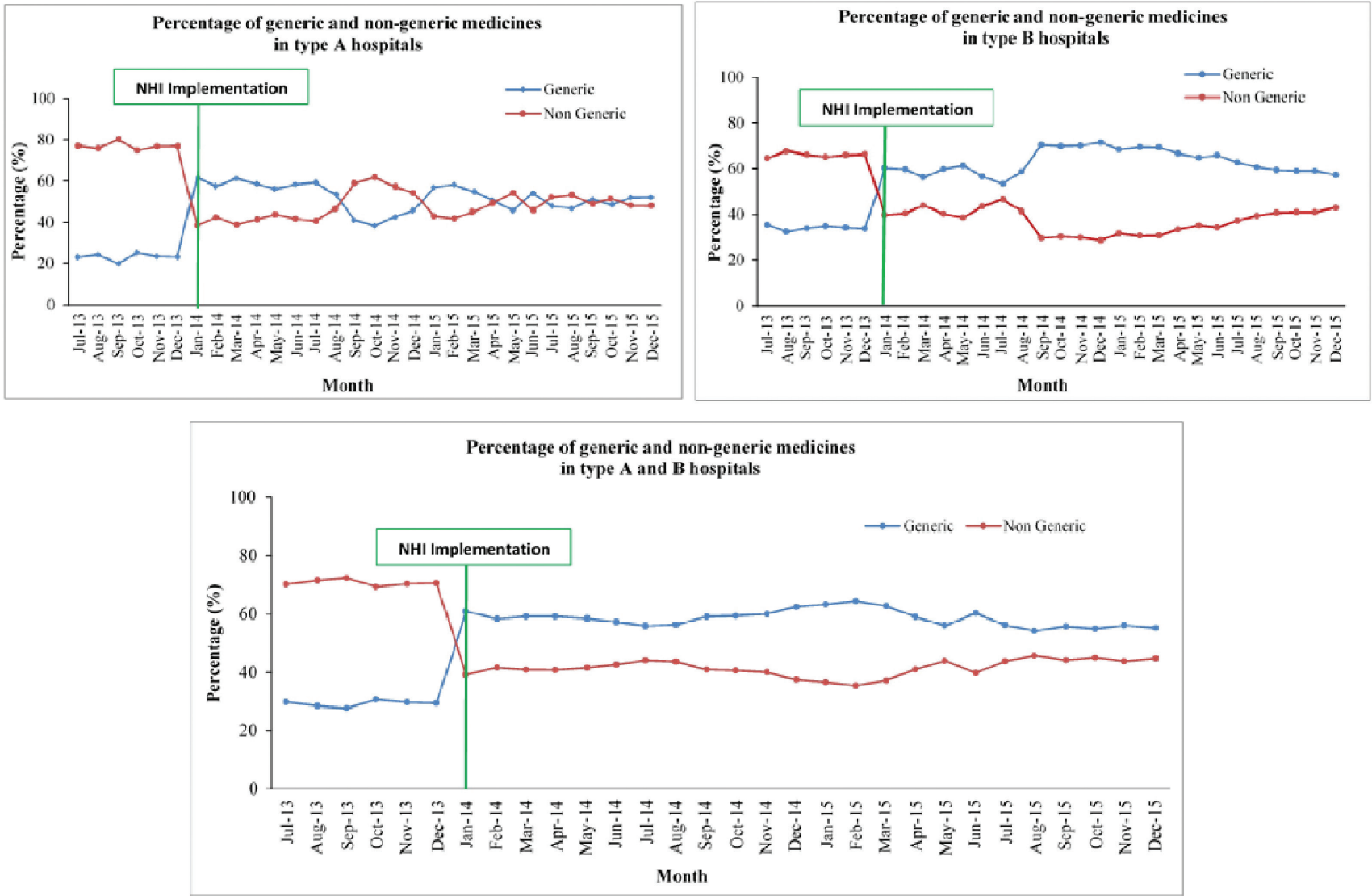

Figure 2. Percentage of generic and non-generic medicines. 


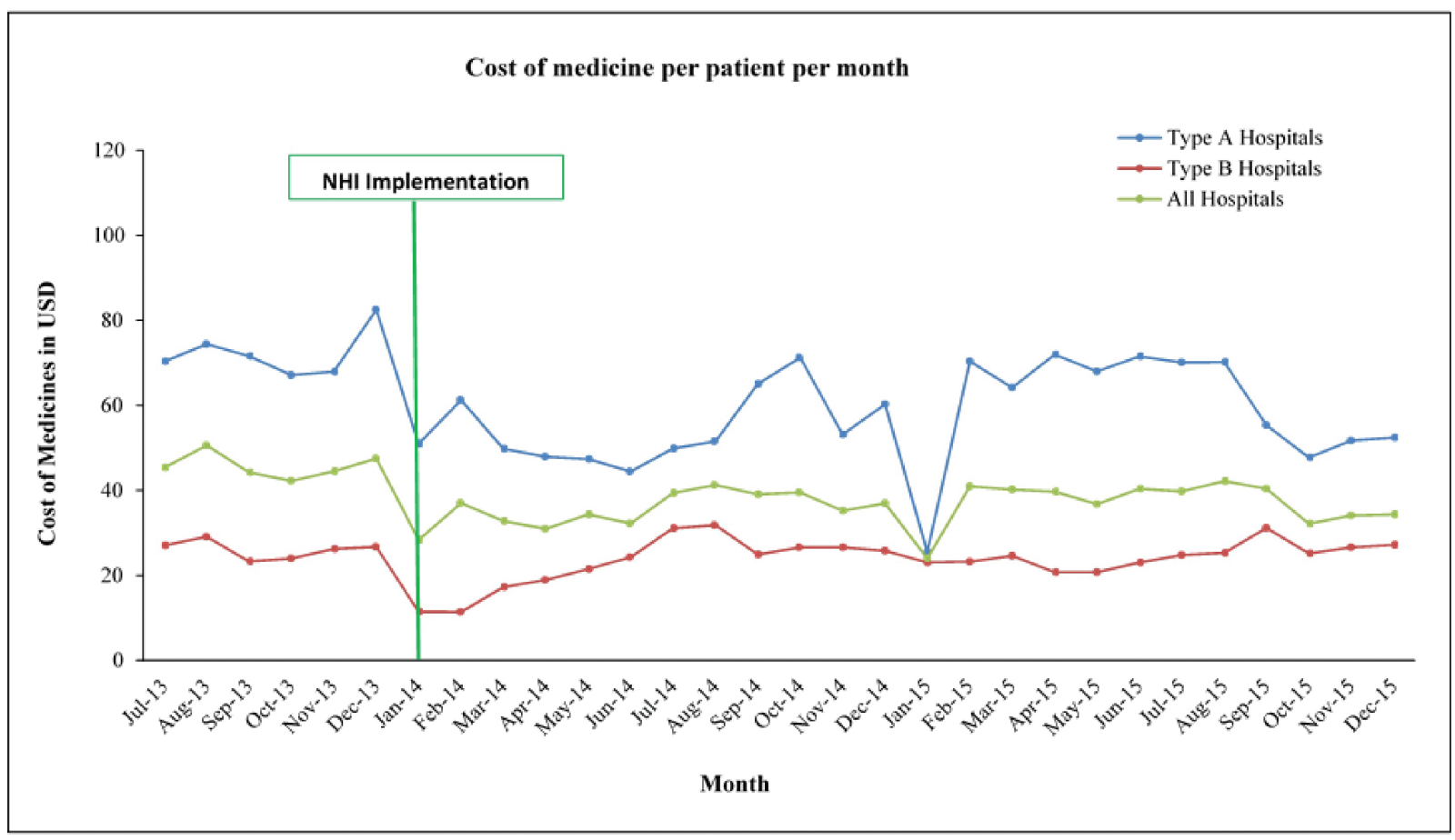

Figure 3. Cost of medicine per patient per month.

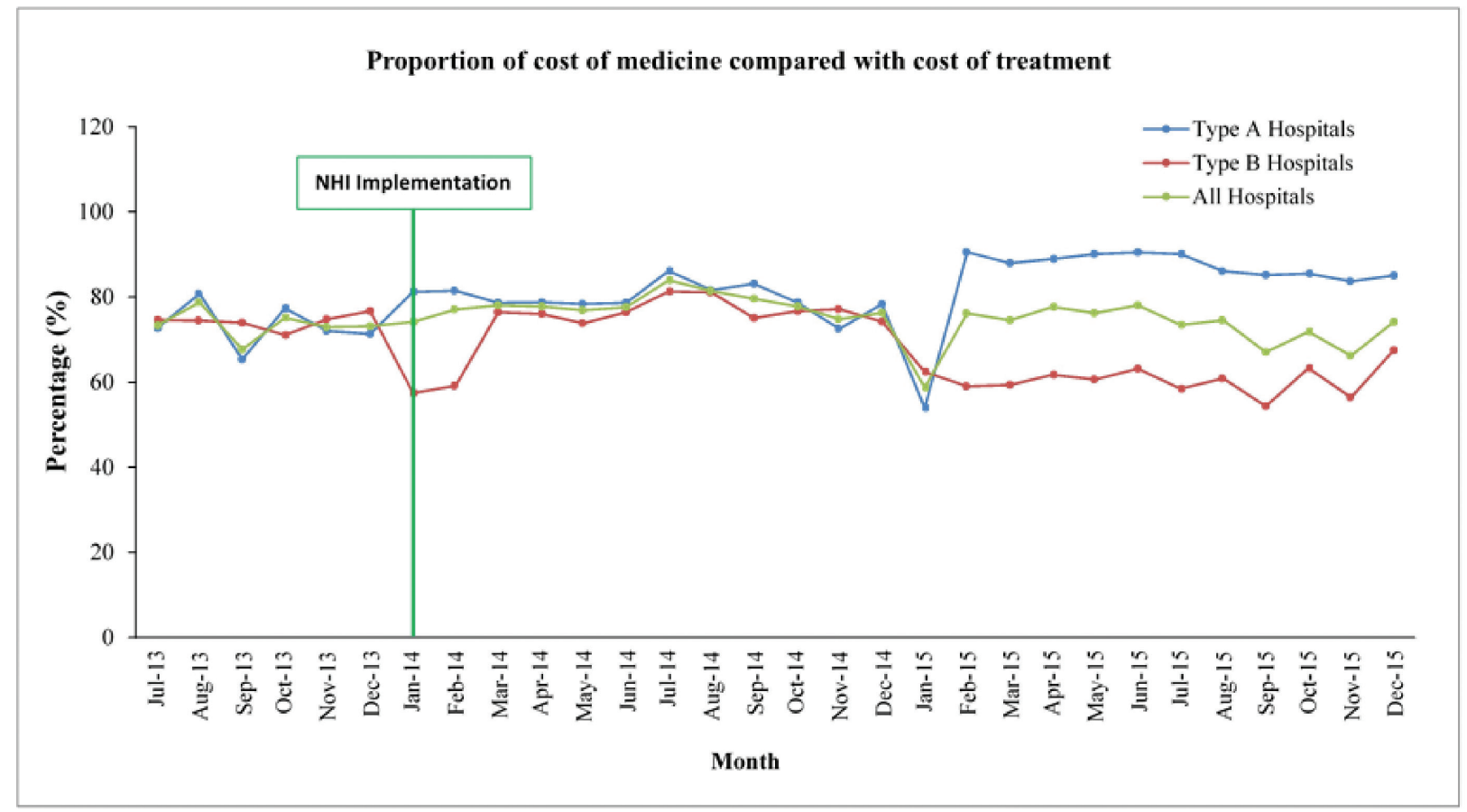

Figure 4. Proportion of cost of medicine compared with cost of treatment.

\section{Proportion of cost of medicines compared with the cost of treatment}

The cost of treatment consists of various costs including medicine cost. The finding showed that medicine cost accounted for the largest part of the treatment cost. Data in the five hospitals showed that the proportion of the cost of medicines compared with the cost of treatment slightly increased at the beginning of the NHI and decreased after 6 months of the implementation of the NHI (Fig. 4). In the type A hospitals, the proportion slightly increased until 1 year of the NHI implementation, but it was not significant in comparison with the data before the NHI implementation. Conversely, the proportion of medicine cost decreased in type B hospitals. 

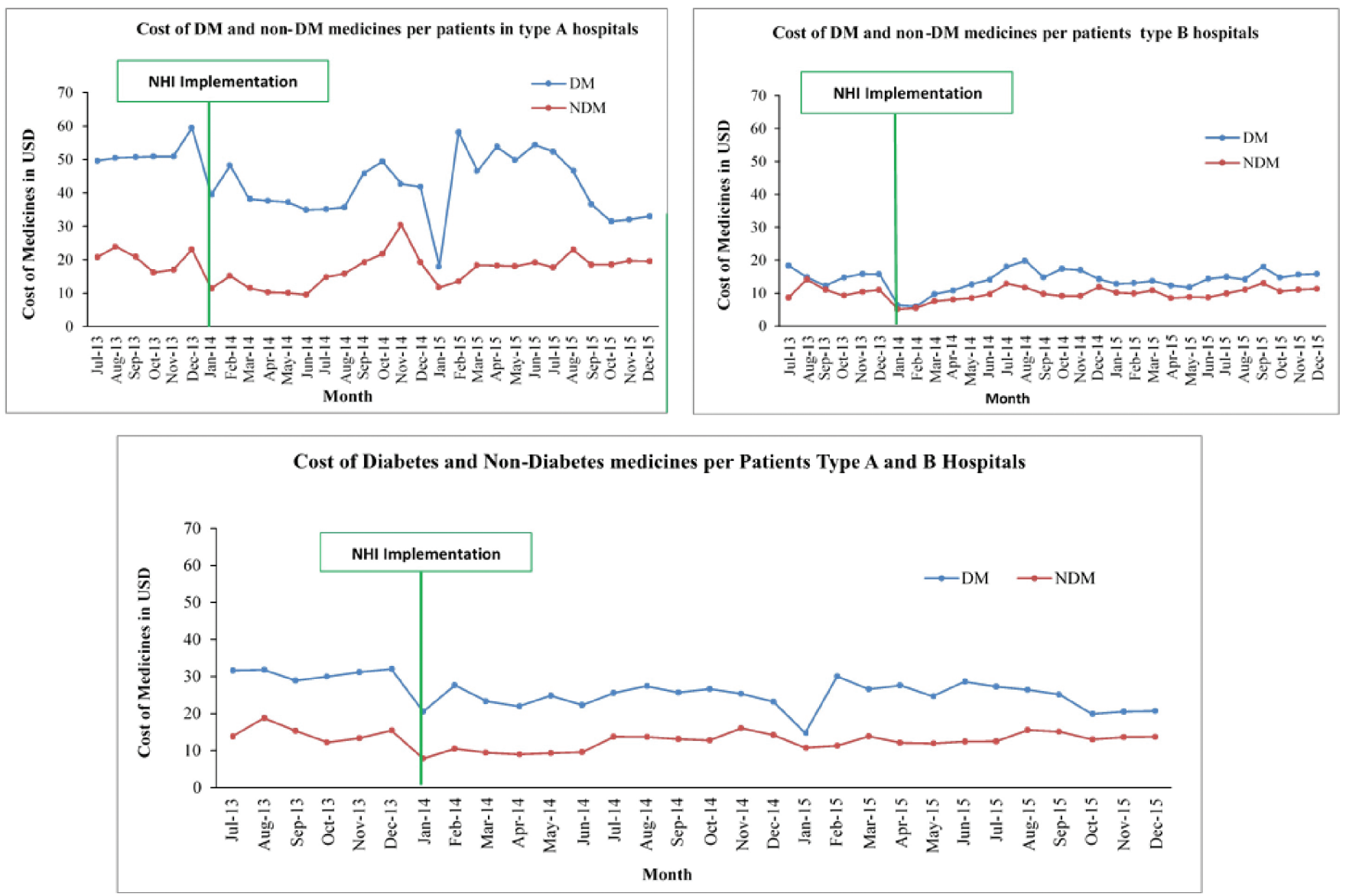

Figure 5. Cost of DM and non-DM medicines per patient per month.

\section{Cost of DM and non-DM medicines}

As shown in Table 1 and Figure 5, the cost of DM medicine decreased significantly after the implementation of the NHI $(p<0.01)$ in the five hospitals and type B hospitals. The cost of DM and non-DM medicines in type A hospitals did not change after the implementation of the NHI. In the type A hospitals, a wide gap was observed, and the cost of DM medicine was dominant. A small gap was documented in the type B hospitals.

\section{DISCUSSION}

This study results confirmed that the implementation of the NHI, followed by the policy reforms on the medicines and the changes in payment methods, had a profound effect on some indicators of medicine profile (i.e., medicines, DM medicines, non-DM medicines, generic medicines, and nongeneric medicines) and on the cost indicators. Different findings were found between the type A and B hospitals. The number of medicines and DM medicines prescribed increased significantly in the type A hospitals, whereas the number of medicines prescribed decreased significantly, followed by a decrease in the number of non-DM medicines among T2DM patients, in type $\mathrm{B}$ hospitals. This different finding between the type A and B hospitals was due to the package rate related to the new payment method (Ina-CBGs) and the complication of the disease, among other reasons. The package rate in type $\mathrm{B}$ hospitals was half that of the type A hospitals (MoH, 2014b). Therefore, the number of medicines prescribed was tighter among patients in the type B than in the type A hospitals mainly for non-DM medicines. Physicians prescribed fewer medicines to minimize the cost of medicines. A non-DM medicine was prescribed selectively in appropriate condition.

This study clarified that the different payment method affected the number of medicines used. One study reported that the new payment system affected medicine use and cost of medicines (Green et al., 2010). The decreasing number of nonDM medicines was related to the non-DM medicines prescribed to treat symptoms and comorbidities (Javanbakht et al., 2011; Lanting et al., 2005). These medicines were not essential to treat the main disease.

The increasing number of medicines prescribed could be affected by the risk of disease complication. T2DM patients in the type A hospitals had a greater risk of disease complication than those in the type B hospitals. In type A hospitals as tertiary health care providers, patients with the poor condition in type B hospitals are referred to type A hospitals $(\mathrm{MoH}, 2014 \mathrm{~b})$. The medicines prescribed increased to treat the main disease and its comorbidities despite the Ina-CBGs code indicating T2DM without complication (MoH, 2014a). Therefore, the appropriate Ina-CBGs code plays a critical role in the hospital to prevent potential loss on the cost of treatment. 
Another important issue related to the implementation of UHC in developing countries was the pattern of generic and non-generic medicines use among T2DM patients. This study found that the number of generic medicines prescribed increased significantly and that of the non-generic medicines decreased significantly in both types A and B hospitals. This condition was affected by the prescription policy under the NHI and Ina-CBGs package rates. Physicians should prescribe medicine based on the national formulary $(\mathrm{MoH}, 2015)$. The national formulary presents a list of medicines that are covered by the NHI. Most of the medicines in the national formulary are generic ones. Therefore, the demand for generic medicines has increased. The increasing use of generic medicines is one of the positive indicators that the pharmaceutical policy goal under the UHC was achieved. Frost and Sullivan (2015) reported that generic demand increased after the implementation of the UHC in Indonesia. However, Indonesia experienced a problem related to the increase in generic demand. The e-catalog procurement system is used to provide medicines under the NHI. At the beginning of the NHI implementation, the e-catalog system was still unstable. Thus, health care facilities could not procure all the medicines through the system. This condition was observed in the type A hospitals. The fluctuation of generic medicines used could be caused by the unavailability of generic medicines in the system.

After the UHC has implemented in 2001 in Mexico, patients who were enrolled by the UHC had easier access to generic medicines, thus increasing the maintenance of blood glucose in Mexico (Sosa-Rubi et al., 2009) The number of generic medicines used increased significantly, but $17.3 \%$ of the patient did not have access to the prescribed medicine because of the limited stocks of generic medicines (Servan-Mori et al., 2015). The use of the national formulary in the health care system is one of the recommendations to improve medicine access (Faden et al., 2011). Low- and lower-middle-income countries, such as Bangladesh, India, Sri Lanka, Vietnam, Philippines, Rwanda, Moldova, Ghana, Ethiopia, and Nigeria, that implement the UHC also have a medicine formulary that is provided free of charge from the insurance (Acharya, 2016).

The Ina-CBGs payment method also contributed to the increasing use of generic medicines. To manage the treatment cost, health care providers tend to use generic medicines. A study on the CBG payment system in China showed that the CBG significantly decreased the examination fee and slightly decreased the total medical cost (Hu et al., 2015). In Korea, the CBG payment system was useful in managing the medical expenditure and did not affect the quality of service (Kwon, 2003). The CBG system in the obstetrics and gynecology department in Korean tertiary hospitals decreased the length of stay of inpatients without increasing the outpatient visits and readmission rates. They also found that the number of surgeries decreased after the implementation of this system (Jung et al., 2018).

The cost of treatment is a critical parameter for analyzing the effect of a new insurance payment method. The decreasing cost of treatment occurred because the health care provider managed the package payment to deliver the services. A similar condition was found in Shenzhen City, China, where the cost of essential medicine decreased because of the effect of health insurance (Zhu, 2008).
To date, evidence showing the effect on the quality of services or treatment is still unavailable in Indonesia.

The average cost of treatment in this study was IDR $636,921 /$ month (USD 48,81/month or USD 581 per year), and the cost of medicines was IDR 480,048/month (36.49/month or 437.9/ year). The cost of treatment in Indonesia was higher than that in Karachi, Pakistan. The study on six hospitals in Karachi, Pakistan, revealed that the cost of treatment was USD 24,23/visit (Ibrahim et al., 2010). However, the cost of treatment in Indonesia was lower than that in China, which had an expenditure for treating T2DM outpatients of 8,397.16 yuan/year (USD 1,214.65/year) (Xu et al., 2016). The high cost of treatment for T2DM was also seen in France; its annual treatment cost for T2DM patients was 4,890 euros (USD 5,868) (Chevreul et al., 2014). McBrien et al. (2013) found that the average 5 -year cost for people aged over 65 years was 44.511 in Canadian dollars. This cost increases in patients with disease complications (Javanbakht et al., 2011). Chevreul et al. (2014) found that medicine cost in France was 17.7 billion euros (USD 21.24 billion) in 2010. In Lithuania, the annual cost for DM without complications was 671.94 euros (USD 764.33 billion) (Domeikiene et al., 2014).

The current study also observed that the proportion of the cost of medicines compared with cost treatment decreased significantly $(p<0.01)$ after the implementation of the NHI from $77.09 \%$ to $71.68 \%$. Despite the decrease in percentage cost, the proportion remained high. In Iran, the proportion of medicine cost was $23.8 \%$ of the total direct cost and that this cost was attributed to the increase in patients with complications (Javanbakht et al., 2011). To increase the efficiency of health care services under the NHI, the proportion of cost of medicine should be reduced. Policy makers should be concerned with the issues related to this. The high proportion of cost medicine to cost treatment can be one of the factors associated with the deficit budget in hospitals and health insurance. In Sudan, number of patients was the main factor contributing to the increase in medicine expenditure of the NHI (Mousnad et al., 2013).

The implementation of the UHC requires long-term monitoring to obtain the evidence to determine the real effect of the UHC on T2DM patients. In Chile, the effectiveness of the implementation of the UHC in T2DM patients was low. Less than $20 \%$ of DM patients showed an $\mathrm{HbA} 1 \mathrm{C}$ of less than $7 \%$ (GuerreroNúñez et al., 2017). In Mexico, the UHC had a significant effect by increasing the blood sugar monitoring and the mean of patients using insulin/oral medication after a 12-year implementation, but it did not have an effect during a 6-year implementation (RiveraHernandez et al., 2016). Evaluations of the long-term effects of universal health coverage on medicine utilization are urgently needed (Garabedian et al., 2012).

NHI as a new system has potential unresolved problems. For example, after the implementation of the NHI in Ghana in 2003 , its responsiveness to the financial needs of health service providers was low until 2014. This condition needs to improve financial viability and service quality (Nsiah-Boateng et al., 2016). Furthermore, the evaluation of the Ina-CBG as a new payment method is required to verify the suitability of this payment method and the quality of services.

In parallel with the payment policy, the pharmaceutical policy can accelerate the effectiveness of the implementation of 
the UHC. The implementation of a pharmaceutical policy in the UHC improved the access to health care services and increased the pharmaceutical consumption in Turkey and Israel (Sax and Shmueli, 2010; Yilmaz et al., 2016). In Israel, pharmaceutical regulation and policy played a role in achieving the cost containment of (public) expenditure on medicines in the implementation of the UHC (Sax and Shmueli, 2010).

The limitation of the study was the data study only representing the patient population in the capital city of Indonesia. There is a need to expand the study to represent other provinces in Indonesia.

\section{CONCLUSION}

The implementation of the NHI positively affected the reduction of medication use and cost of treatment and the increase in the use of generic medicines. However, the high cost of medicines requires attention to prevent inefficiency in treatment.

\section{REFERENCES}

Acharya, M. Adapting pharmaceutical pricing and reimbursement strategies for achieving universal health coverage in nepal: lessons from selected low- and lower-middle-income countries. Indian J Pharm Sci, 2016; 78(5):9.

Benjamin L, Buthion V, Vidal-Trécan G, Briot P. Impact of the healthcare payment system on patient access to oral anticancer drugs: an illustration from the French and United States contexts. BMC Health Serv Res, 2014; 14:274.

BPJS. The role of Health Social Security Administrative Body (BPJS) for health in increasing health services. 2017. Jakarta, Indonesia: BPJS.

Chawla M, Ellis RP. The impact of financing and quality changes on health care demand in Niger. Health Policy Plan, 2000; 15(1):76-84.

Chevreul K, Berg BK, Bouché C. The burden and treatment of diabetes in France. Global Health, 2014; 10:6.

Domeikiene A, Vaivadaite J, Ivanauskiene R, Z. Padaiga Z. Direct cost of patients with type 2 diabetes mellitus healthcare and its complications in Lithuania. Medicina (Kaunas), 2014; 50(1):54-60.

Faden L, Vialle-Valentin C, Ross-Degnan D, Wagner A. Active pharmaceutical management strategies of health insurance systems to improve cost-effective use of medicines in low- and middle-income countries: a systematic review of current evidence. Health Policy, 2011; 100(2):134-43

Frost and Sullivan. Market trends: impact of Indonesia's national healthcare scheme. CA, 2015.

Garabedian LF, Ross-Degnan D, Ratanawijitrasin S, Stephens $\mathrm{P}$, Wagner AK. Impact of universal health insurance coverage in Thailand on sales and market share of medicines for non-communicable diseases: an interrupted time series study. BMJ Open, 2012; 2(6).

Green CJ, Maclure M, Fortin PM, Ramsay CR, Aaserud M, Bardal S. Pharmaceutical policies: effects of restrictions on reimbursement. Cochrane Database Sys Rev, 2010(8):CD008654.

Guerrero-Núñez S, Valenzuela-Suazo S, Cid-Henríquez P. Effective universal coverage of diabetes mellitus type 2 in Chile. Rev Lat Am Enfermagem, 2017; 25:e2871.

Hu W-Y, Yeh C-F, Shiao A-S, Tu T-Y. Effects of diagnosisrelated group payment on health-care provider behaviors: a consecutive three-period study. J Chin Med Assoc, 2015; 78(11):678-85.

Ibrahim WN, Aljunid S, Ismail A. Cost of type 2 diabetes mellitus in selected developing countries. Malaysian Journal of Public Health Medicine, 2010; 10(2):4.

IDF. IDF Diabetes Atlas Seventh Edition. 2015. Contract No.: ISBN number: 978-2-930229-81-2. [ONLINE] Available at www. diabetesatlas.org. [Accessed 03 September 2018].
Indonesian Association of Endocrinology. 2015. Consensus on diabetes mellitus management in Indonesia. Jakarta, Indonesia. [ONLINE] Available at http://pbperkeni.or.id. [Accessed 05 September 2018].

Javanbakht M, Baradaran HR, Mashayekhi A, Haghdoost AA, Khamseh ME, Kharazmi E, Sadeghi A. Cost-of-illness analysis of type 2 diabetes mellitus in Iran. PLoS One, 2011; 6(10).

Jung YW, Pak H, Lee I, Kim EH. The effect of diagnosisrelated group payment system on quality of care in the field of obstetrics and gynecology among Korean Tertiary Hospitals. Yonsei Med J, 2018; 59(4):539-45.

Kwon S. Payment system reform for health care providers in Korea. Health Policy Plan, 2003; 18(1):84-92.

Lanting LC, Joung IM, Mackenbach JW, Bootsma AH. Ethnic differences in mortality, end-stage complications, and quality of care among diabetic patients: a review. Diabetes Care, 2005; 28(9):2280-8.

McBrien KA, Manns BJ, Chui B, Klarenbach SW, Rabi P, Ravani P, Hemmelgarn B, Wiebe N, Au F, Clement F. Health care costs in people with diabetes and their association with glycemic control and kidney function. Diabetes Care, 2013; 36(5):1172-80.

$\mathrm{MoH}$. The regulation of MoH No.69 "Standardize of rate of healthcare in the first and advance health facilities in the implementation of NHI". MoH, Jakarta, Indoneisa, 2013.

MoH. Regulation of MoH No. 27 about technical guideline INACBGs system. MoH, Jakarta, Indoneisa, 2014a.

$\mathrm{MoH}$. The regulation of $\mathrm{MoH}$ No.59 "Standardize of rate of healthcare in the implementation of NHI". MoH, Jakarta, Indoneisa, 2014b.

$\mathrm{MoH}$. The report of accountability performance year 2014 . $\mathrm{MoH}$, Jakarta, Indoneisa, 2015.

Mousnad MA SA, Ibrahim MIM. Determination of the main factors contributing to increases in medicine expenditures for the National Health Insurance Fund in Sudan. J Pharm Health Serv Res, 2013;6.

Mousnad MA, Ibrahim MIM, Palaian S and Shafie AA. Medicines utilization and trends in Sudan between 2006 and 2010. Trop J Pharm Res, 2017; 16(7):1717-28.

Nsiah-Boateng E AM, Asenso-Boadi F, Andoh-Adjei F-X. Value and services quality assessment of the national health insurance scheme in Ghana: evidence from Ashiedu Keteke District. Value Health Reg Issues, 2016; $10: 7$.

Presidential Decree. Indonesian Presidential Decree No. 111 year 2013 changes of Indonesian Presidential Decree No. 12 Year 2013 about health insurance. Jakarta. [ONLINE] Available at http://depkes.go.id. [Accessed 04 September 2018].

Rivera-Hernandez M, Rahman M, Mor V, Galarraga O. The impact of social health insurance on diabetes and hypertension process indicators among older adults in Mexico. Health Serv Res, 2016; 51(4):1323-46.

Sax P, Shmueli A. Impact of pharmaceutical regulation and policies on health system performance goals in Israel. Adv Health Econ Health Serv Res, 2010; 22:77-101.

Servan-Mori E, Heredia-Pi I, Montañez-Hernandez J. Access to medicines by Seguro Popular beneficiaries: pending tasks towards universal health coverage. PLoS One, 2015; 10(9):e0136823.

Sosa-Rubi SG, Galarraga O, Lopez-Ridaura R. Diabetes treatment and control: the effect of public health insurance for the poor in Mexico. Bull World Health Organ, 2009; 87(7):512-9.

Stewart MT, Horgan CM. Health services and financing of treatment. Alcohol Res Health, 2011; 33(4):389-94.

Wagner AK, Soumerai SB, Zhang F, . Ross-Degnan D. Segmented regression analysis of interrupted time series studies in medication use research. J Clin Pharm Ther, 2002; 27(4):299-309.

Wijaya IN, Faturrohmah A, Yuda A, Mufarrihah, Soesanto TG, Kartika D, Agustin WW, Putri HPNS. Profile of medicine used among diabetes mellitus patients in PUSKESMAS EAST SURABAYA. Jurnal Farmasi Komunitas, 2015; 2(1):6. 
Xu GC, Luo Y, Li Q, Wu MF, Zhou ZJ. Standardization of type 2 diabetes outpatient expenditure with bundled payment method in China. Chin Med J, 2016; 129(8):953-9.

Yilmaz EA KG, Yenilmaz FB, Saylan M, Tatar M, Akbulat A, Gürsöz H, Kerman S. Impact of health policy changes on trends in the pharmaceutical market in Turkey. Value Health Reg Issues. 2016; 10:5.

Zhu M, Xinping Z, Shengchun T, Liquin L. The influence of health insurance towards accessing essential medicines: the experience frrom Shenzhen labor health insurance. Health Policy, 2008; 88:10.

\section{How to cite this article:}

Anggriani Y, Purwanggana A, Pontoan J, Restinia M. The impacts of the health policy reform under the national health insurance on medicine use and treatment cost: A study on type-2 diabetic mellitus patients in Jakarta, Indonesia. J Appl Pharm Sci, 2019; 9(12):078-087. 